\title{
ROLE OF TRANEXAMIC ACID IN REDUCING POSTOPERATIVE BLOOD LOSS AND TRANSFUSION REQUIREMENT IN PATIENTS UNDERGOING LOWER LIMB ORTHOPEDIC SURGERIES
}

\author{
Yashwant Dhawle ${ }^{1}$, Ashish Mathur ${ }^{2}$, Satish Kumar Ahirwar ${ }^{3}$
}

\section{HOW TO CITE THIS ARTICLE:}

Yashwant Dhawle, Ashish Mathur, Satish Kumar Ahirwar. "Role of Tranexamic Acid in Reducing Postoperative Blood Loss and Transfusion Requirement in Patients Undergoing Lower Limb Orthopedic Surgeries". Journal of Evolution of Medical and Dental Sciences 2014; Vol. 3, Issue 44, September 15; Page: 10820-10827, DOI: $10.14260 /$ jemds/2014/3410

\begin{abstract}
AIM: Aim of our study to assess the effects of tranexamic acid (TA) in patients undergoing lower limb orthopedic surgeries. OBJECTIVE: Assess the effects of tranexamic acid on prevention of bleeding and requirement of blood transfusion after major lower limb orthopedic surgeries. MATERIAL AND METHOD: 90 patients ASA grade I \& II undergoing elective surgery for femoral fracture like open reduction internal fixation, hemiarthroplasty, total hip replacement (THR) under anaesthesia were taken. Patients were classified randomly into 2 groups (forty five patients in each group). Group T: Patients received inj. TA $10 \mathrm{mg} / \mathrm{kg}$ body weight. Group P: Patients received normal saline $1 \mathrm{ml} / \mathrm{kg}$ body weight $15 \mathrm{~min}$ before surgery. Postoperative hemoglobin concentration (on day 0 and day 2) and volume of blood in the drain were measured. The number of units of packed red cells transfused during the hospital stay was recorded and any thromboembolic and other complications were documented. RESULT: Analysis revealed that there were no significant differences between the patients with respect to age, sex, duration and type of surgery and preoperative mean hemoglobin concentration. Neither heart rate nor MABP has statistically significant difference or results $(\mathrm{P}>0.05)$. The drains were removed in the evening of the first postoperative day. Mean volume of blood in the drain compared to placebo group showing a highly significant reduction in postoperative blood loss $(\mathrm{P}=0.01)$. Mean fall in hemoglobin at day 0 and day 2 was 2 less in the study group as compared to the placebo that has P value 0.01 making it significant finding. CONCLUSION: the present paired study demonstrated that the administration of TA given preoperatively reduces the blood loss in the first $24 \mathrm{~h}$ by a highly significant degree as well it causes a significant reduction in postoperative anemia and need for transfusion among these patients.
\end{abstract}

KEYWORDS: Tranexamic acid, orthopedic surgeries reduce blood loss.

INTRODUCTION: Major orthopedic surgeries are commonly associated with marked blood loss, and a subsequent need for blood transfusion is often encountered. The causes of bleeding are multifactorial, increased fibrinolytic activity being one of them. Several approaches have been used to reduce intraoperative blood loss, including: Hypotensive anesthesia and the use of allogenic blood products.

Hip fracture is commonly encountered clinical problems, which are associated with a one year mortality rate of about 25\% (Davidson-2001).(1) In recent years, studies have documented a rapidly increasing incidence of hip fractures especially in elderly patients (Adunsky A-2003).(2) Surgery for hip fractures frequently requires blood transfusion, despite recent advances in techniques of orthopedic surgery and mechanical improvements of implants. Blood may be transfused before, during or following surgery. 
In the United State, surgery for hip fractures ranks second in total number of units of blood administered to patients according to diagnoses groups (Friedman, B.A. -1979).(3) The use of allogeneic blood products increases the rate of transmission of infectious diseases, modulates the immune response, and increases the risk of postoperative infection.

Numerous methods of controlling bleeding such as thromboplastic agents; topical freezing saline; deliberate hypotension; and administration of fibrinolytic inhibitors (such as aprotinin and tranexamic acid) have been used (Bannister GC-1990).(4) Tranexamic acid has been used in urological, gynecological and thoracic surgery (Verstraete M-1985),(5) but has not routinely been used in total hip surgery (Ido K, Neo M-2000).(6)

In hip fracture surgery, however, tranexamic acid has not been used because its effectiveness is still unknown, and a few studies have been published. The goal of this prospective, randomized study was to determine the effect of a single bolus dose of tranexamic acid, given intravenously at the beginning of the operation, on blood loss as well as on need for blood transfusions in hip fracture surgery.

Tranexamic acid (TA) is an analogue of lysine, (Astedt B-1987)(7) which has powerful antifibrinolytic potency through blocking the lysine-binding sites of plasminogen molecule and is mainly used in bleeding caused by acute or chronic, localized or systemic accentuation of fibrinolysis.

Early in 1988, some investigators suggested giving TA before the release of tourniquet for its effectiveness on reducing blood loss after TKA. (Benoni G -1995)(8) From then on, a series of clinical trials have been done to verify this assumption. However, the use of TA still remains controversial.

MATERIAL \& METHODS: After obtaining informed consent this randomized study was conducted in Gandhi Medical College Bhopal, M.P. in which 90 patients ASA grade I \& II undergoing elective surgery for femoral fracture like open reduction internal fixation, hemiarthroplasty, total hip replacement (THR) under anaesthesia were taken.

After taking a detailed history, thorough general physical examination, and all pertinent investigation were carried out to exclude any systemic disease. Exclusion criteria for this study were patient refusal to participate in the study, patient less than 20 year or more than 60 year of age, patient weighing less than $40 \mathrm{~kg}$, patient with $\mathrm{BMI}>35$ and patients with any sever systemic disease.

Patients were classified randomly into 2 groups (forty five patients in each group):

Group T: Patients received inj. TA $10 \mathrm{mg} / \mathrm{kg}$ body weight.

Group P: Patients received normal saline $1 \mathrm{ml} / \mathrm{kg}$ body weight.

Preoperatively, the hemoglobin concentration, bleeding time, clotting times were measured on the day before operation. In the operation theater, all the baseline parameters, such as heart rate (HR), electrocardiography (ECG), non-invasive blood pressure (NIBP), pulse oxymetry (SPO2) were recorded and $\mathrm{i} / \mathrm{v}$ access was established. All patients in the study group received a bolus intravenous injection of $10 \mathrm{mg} / \mathrm{kg}$ TA through $50 \mathrm{ml}$ syringe over $15 \mathrm{~min}$. about $15 \mathrm{~min}$ before incision.

Patients in the placebo group received normal saline as a bolus intravenous injection of $50 \mathrm{ml}$ over $15 \mathrm{~min}$ before the surgery. The anesthetist administrating the drug was unaware of $50 \mathrm{ml}$ being given. Surgery was performed under combined spinal epidural anesthesia with $0.5 \%$ bupivacaine heavy (hyperbaric). During induction, an epidural catheter was also inserted to provide postoperative analgesia. 
Hemodynamics (heart rate; systolic, diastolic and mean arterial blood pressure (MABP)) was noted starting from preoperational to shifting at regular intervals of $30 \mathrm{~min}$. Ringer's solution was used as the replacement fluid for the estimated intraoperative blood volume lost in a 3:1 ratio. There was no significant difference in amount of fluid in both the groups.

Postoperative hemoglobin concentration (on day 0 and day 2) and volume of blood in the drain were measured. The number of units of packed red cells transfused during the hospital stay was recorded and any thromboembolic and other complications were documented. A criterion for blood transfusion was a reduction in hemoglobin exceeding $25 \%$ of preoperative level.

For tests of differences between quantitative data, two-sided t-tests were used. In the test, data are presented as mean \pm standard deviation (SD) and $\mathrm{P}<0.05$ are considered significant.

RESULT \& ANALYSIS: There were no significant differences between the patients with respect to age, sex, duration and type of surgery and preoperative mean hemoglobin concentration [Table 1 and Figure 1]. Neither heart rate nor MABP has statistically significant difference or results $(\mathrm{P}>0.05)$.

The drains were removed in the evening of the first postoperative day. Mean volume of blood in the drain was $39.33 \pm$ as compared to $91.11 \pm$ in placebo group showing a highly significant reduction in postoperative blood loss $(\mathrm{P}=0.01)$ [Figure 2].

Mean fall in hemoglobin at day 0 was $2.99 \pm 3.457$ in the study group as compared to $7.70 \pm 6.05$ in the placebo that has $P$ value 0.01 making it significant finding [Figure 3]. Similar to this fall in hemoglobin at day 2 in the study group was $0.4 \pm 0.744$ and in the placebo was $2.7122 \pm 2.70$ with $P$ value 0.000 again showing statistically significant [Table2].

In our study out of 45 patients, 18 patients who fell in the placebo group required blood transfusion and while seven patients out of 45 in the study group need a transfusion $(\mathrm{P}=0.01)$. No significant complications like thromboembolic episodes were encountered in both the groups.

DISCUSSION: Bleeding during hip fracture surgery is an important problem. An excessive bleeding from femur canal into peripheral compartments occurs immediately after fracture and before surgery. The mechanisms of bleeding during and after hip surgery are supposed to be defective surgical hemostasis, platelets dysfunction (drug-induced), consumptive coagulopathies and increased fibrinolytic activity.

In an attempt to decrease surgical bleeding and perioperative allogenic blood transfusion requirements, several techniques- such as autologous blood transfusion, perioperative blood salvage, deliberate hypotension, and administration of fibrinolytic inhibitors have been developed.(4)

However, these approaches also have some disadvantages, such as the time limit of blood preservation, the use of expensive devices, and the insufficient blood correction in intraoperative blood saving. Altogether, the use of a pneumatic tourniquet as well as surgery enhances coagulation and fibrinolysis. Tranexamic acid saturates the lysine binding sites of human plasminogen, displacing plasminogen from the fibrin surface, which results in inhibition of fibrinolysis. ${ }^{(5)}$

It is useful in a wide range of hemorrhagic conditions such as cardiac surgery, acute upper gastrointestinal bleeding, oral surgery, liver transplantations and gynecologic bleedings. (Dunn CJ1999). ${ }^{(9)}$ 
In 2008, 615050 total knee replacements were performed in the United States adult population, 134\%more than in 1999.(Losina E -2012).(10) The number of patients receiving TKA increases nowadays, which largely raises the risks of allogenic blood transfusion and heavily burdens the pub- lic health system. TA is cheap and very efficacious in reducing blood loss. Therefore, it is a very promising drug to lower these risks.

TA inhibits fibrinolysis mainly by blocking the lysine binding sites of plasminogen.. (Mahdy AM -2011).(11) Plasminogen binds to fibrin at this site and results in clot breakdown. Tissue plasminogen activator is a major enzyme responsible for conversion of plasminogen into active plasmin. Surgery and venous stasis increase the release of tissue plasminogen activator and activate the fibrinolytic system.

Binding of TA to plasminogen prevents the breakdown of fibrin even though plasmin is generated. ${ }^{11}$ For TA to be effective; it has to interact with the plasminogen binding site before binding to fibrin takes place. (Benoni G -2000),(12) (Krishnamurti C-1994)(13) The fibrinolytic response after surgery is biphasic.(Eriksson BI-1991)(14) The initial phase of increased fibrinolytic activity lasts one hour and is followed by fibrinolytic shutdown, which peaks again after about 24 hours. This is a consequence of increased release of plasminogen activator inhibitor.

Several studies have investigated the effect of TA on intraoperative and postoperative blood loss in patients undergoing orthopedic surgeries but the efficacy of such treatment has not yet been clearly established. In this study, we found that preoperative administration of TA significantly reduces the postoperative blood loss in hip and femoral surgeries, which was indicated by volume of blood in drain and fall in hemoglobin postoperatively.

Similar study was conducted by (Sadeghi and Mehraein-2006) ${ }^{[15]}$ to see the effect of TA on hip fracture surgery. They found perioperative blood loss significantly lower in the TA group $(\mathrm{P}<0.03)$. Postoperative drainage was lower in TA group $(\mathrm{P}<0.195)$. There were no differences in coagulation parameters. The rates of transfused patients in TA and control groups were $37 \%$ and $57 \%$.

Our results are in accordance with, authors that shown tranexamic acid to be of use in reducing blood loss and transfusion requirements in knee arthroplasty and scoliosis surgery. Good L.2003,(16) Jansen AJ, Andreica S, -1999,(17) Neilipovitz DT, Murto K, Hall L-2001.(18)

Other studies like of Benoni et al-1996,(19) administered TA intravenously before tourniquet release and then $3 \mathrm{~h}$ later in patients undergoing TKA, and reported that the intra and postoperative blood loss were reduced to one-third as a result. However, in contrast to elective hip or knee surgery; in hip fracture, the fibrinolytic system is activated by trauma and increased during surgery. So we used a single bolus dose of TA approximate 15 min prior to skin incision.

Ekbäck et al-2000.(20) Showed that the perioperative blood loss was significantly lower in the TA-treated group than in the control group. Postoperative drainage bleeding was correspondingly less $(\mathrm{P}=0.001) \cdot{ }^{[21]}$

Yamasaki et al-2005.[21] in their study on cement less THR found a reduction in total blood loss in the TA group than in the control group $(\mathrm{P}<0.01)$.

This study also demonstrates that transfusion requirements also reduced in the study group.

A meta-analysis of nine randomized control trial reveals that use of TA in TKR significantly reduces the proportion of patients requiring blood transfusion Cid J, Lozano-2005.[22] 
This study is said that TA increase hypercoagulability and can lead to chance of thromboembolic episodes, but we did not face any abnormal finding. Benoni et al. also suggested that TA does not affect risk of DVT because it inhibits fibrinolysis in the wound not in circulation

CONCLUSION: In conclusion, the present paired study demonstrated that the administration of TA given preoperatively reduces the blood loss in the first $24 \mathrm{~h}$ by a highly significant degree as well it causes a significant reduction in postoperative anemia and need for transfusion among these patients. This would in turn, help avoid complications related with transfusion of blood and blood products. However, further investigation is necessary to determine the effectiveness.

\begin{tabular}{|l|c|c|c|}
\hline \multicolumn{1}{|c|}{ Parameters } & Placebo (n=45) & Study (n=45) & P value \\
\hline Sex (M/F) & $10 / 35$ & $10 / 35$ & NA \\
\hline Duration of surgery (min) & $118.7 \pm 6.3$ & $117.3 \pm 10.7$ & 0.5 \\
\hline Preoperative hemoglobin & $10.9 \pm 1.3$ & $10.5 \pm 1.4$ & 0.2 \\
\hline \multicolumn{2}{|c|}{ Table 1: Patient characteristics, laboratory and surgical data } \\
\hline
\end{tabular}

Values are given in mean \pm standard deviation

\begin{tabular}{|l|c|c|c|}
\hline \multicolumn{1}{|c|}{ Parameter } & Placebo & Study & P value \\
\hline Volume of blood in drain Postoperative & $91.1 \pm 17.6$ & $39.3 \pm 10.1$ & 0.01 \\
\hline Hemoglobin concentration Day 0 & $9.9 \pm 0.8$ & $10.1 \pm 1.0$ & 0.00 \\
\hline Day 2 & $9.6 \pm 0.8$ & $10.1 \pm 1.0$ & 0.00 \\
\hline Percentage fall of hemoglobin at day 0 (from baseline) & $7.7 \pm 6.0$ & $2.99 \pm 3.5$ & 0.01 \\
\hline Percentage fall of hemoglobin at day 2 (from day 0) & $2.7 \pm 2.7$ & $0.4 \pm 0.7$ & 0.00 \\
\hline \multicolumn{2}{|c|}{ Table 2: Postoperative volume of blood in drain and \% fall in hemoglobin } \\
\hline
\end{tabular}

Values are given in mean \pm standard deviation. Day $0=$ Day of surgery.

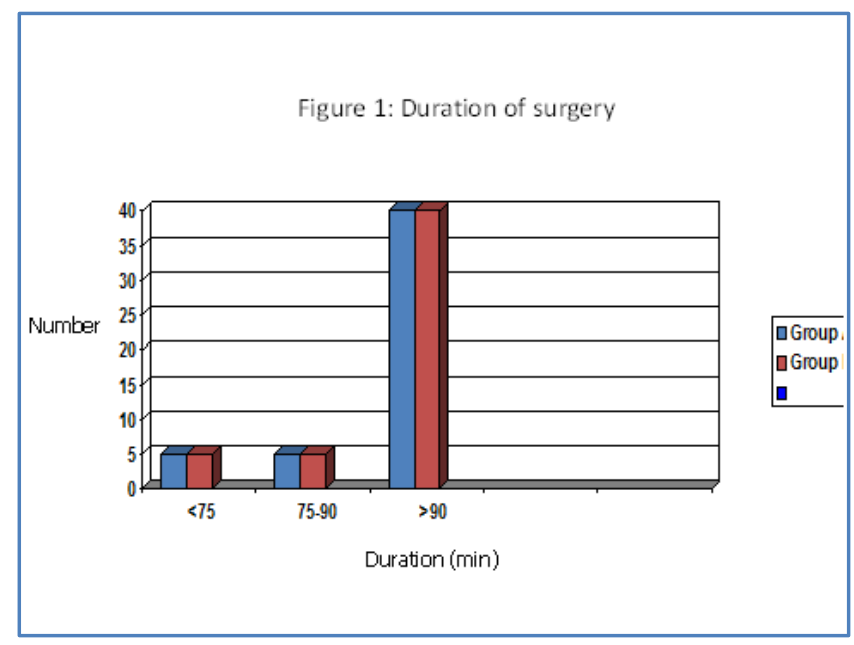



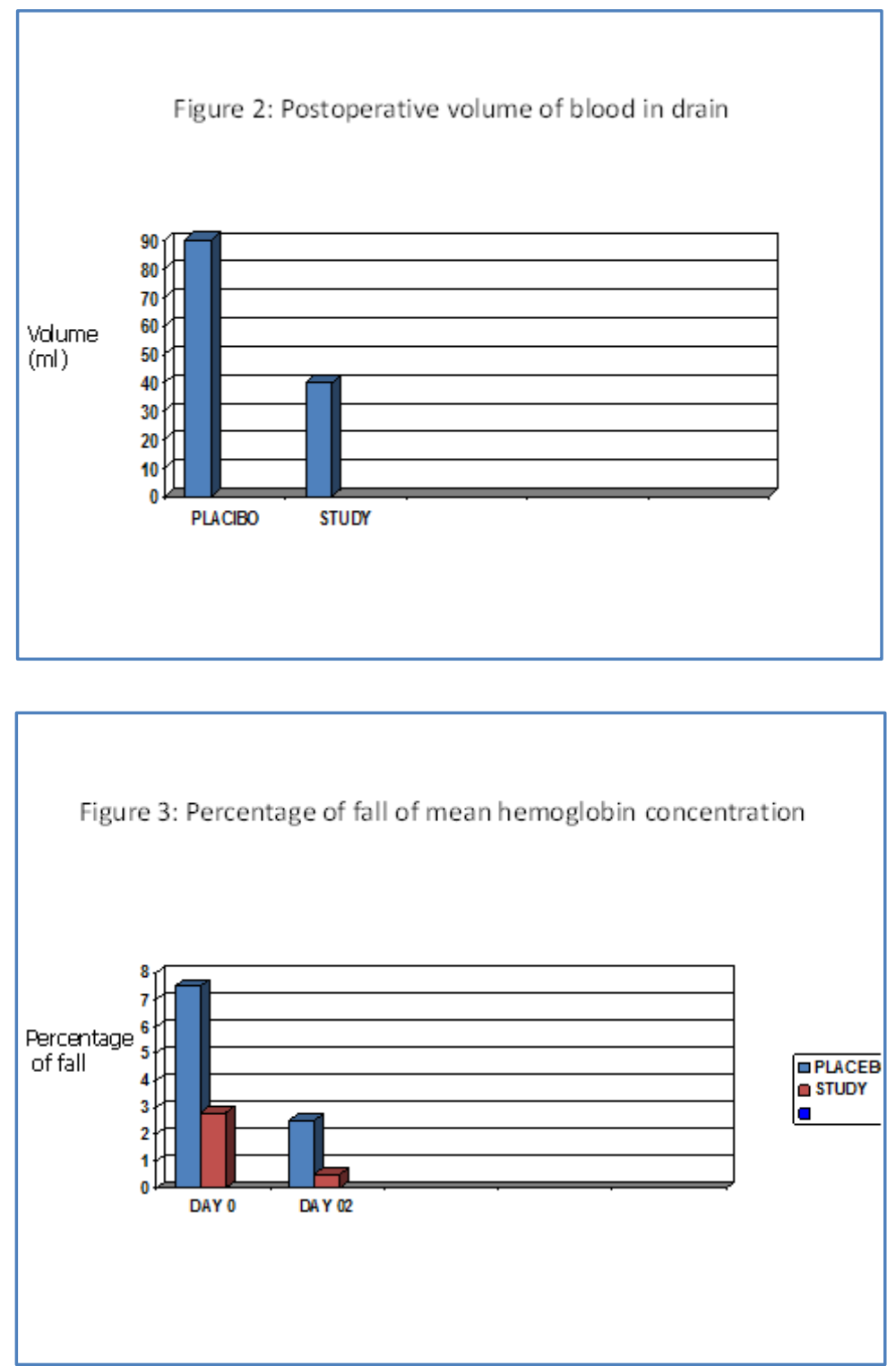

\section{REFERENCES:}

1. Davidson CW, Merrilees MJ, Wilkinson TJ, McKie JS, Gilchrist NL. Hip fracture mortality and morbidity- can we do better? N Z Med J. 2001 Jul 27; 114 (1136): 329- 332.

2. Adunsky A., Lichtenstein A., Mizrahi E., Arad M, Heim M. Blood transfusion requirements in elderly hip fracture patients. Arch Gerontol Geriatr. 2003 Jan- Feb; 36 (1): 75-781

3. Friedman, B.A. An analysis of surgical blood use in United States hospitals with application to the maximum surgical blood order schedule, Transfusion.1979 May-Jun; 19 (3): 268-278.

4. Bannister GC, Young SK, Baker AS, Mackinnon JG, Magnusson PA. Control of bleeding in cemented arthroplasty. J Bone Joint Surg Br. 1990 May; 72 (3): 444-446.

5. Verstraete M. Clinical application of inhibitors of fibrinolysis. Drugs. 1985 Mar; 29 (3): 236-261. 
6. Ido K, Neo M, Asada Y, Kondo K, Morita T, Sakamoto T, Hayashi R. Reduction of blood loss using tranexamic acid in total knee and hip arthroplasties. Arch Orthop Trauma Surg. 2000; 120 (9): 518-520.

7. Astedt B. Clinical pharmacology of tranexamic acid. Scand J Gastroenterol Suppl 1987; 137: 22-5.

8. Benoni G, Carlsson A, Petersson C, et al. Does tranexamic acid reduce blood loss in knee arthroplasty? Am J Knee Surg 1995; 8 (3): 88-92.

9. Dunn CJ, Goa KL. Tranexamic acid: A review of its use in surgery and other indications. Drugs. 1999 Jun; 57 (6): 1005-1032.

10. Losina E, Thornhill TS, Rome BN, et al. The dramatic increase in total knee replacement utilization rates in the United States cannot be fully explained by growth in population size and the obesity epidemic. J Bone Joint Surg Am 2012; 94 (3): 201-7.

11. Mahdy AM, Webster NR. Perioperative systemic haemostatic agents. Br J Anaesth 2004; 93: 842-58.

12. Benoni G, Lethagen S, Nilsson P, Fredin H. Tranexamic acid, given at the end of the operation, does not reduce postoperative blood loss in hip arthroplasty. Acta Orthop Scand 2000; 71: 250-4.

13. Krishnamurti C, Vukelja SJ, Alving BM. Inhibitory effects of lysine analogues on t-PA induced whole blood clot lysis. Thromb Res 1994; 73: 419-30.

14. Eriksson BI, Hultman E, Martinell S, Eriksson E, Tengborn L, Risberg B. Regional fibrinolysis following total hip replacement. Thromb Res 1991; 62: 441-7.

15. Sadeghi M, Mehr-Aein A. Does a single bolus dose of tranexamic acid reduce blood loss and transfusion requirements during hip fracture surgery? A prospective randomized double blind study in 67 patients. Acta Medica Iranica 2006; 45: 431-6. http://www.sid.ir/en/VEWSSID/J_ pdf/86520070601.pdf.

16. . Good L., Peterson E., Lisander B. Tranexamic acid decreases external blood loss but not hidden blood loss in total knee replacement. Br J Anaesth. 2003 May; 90 (5): 596-599.

17. Jansen AJ, Andreica S, Claeys M, D'Haese J, Camu F, Jochmans K. Use of tranexamic acid for an effective blood conservation strategy after total knee arthroplasty. Br J Anaesth. 1999 Oct; 83 (4): 596-601.

18. . Neilipovitz DT, Murto K, Hall L, Barrowman NJ, Splinter WM. A randomized trial of tranexamic acid to reduce blood transfusion for scoliosis surgery. Anesth Analg. 2001 Jul; 93 (1): 82-87.

19. . Benoni G, Fredin H. Fibrinolytic inhibition with tranexamic acid reduces blood loss and blood transfusion after knee arthroplasty: A prospective, randomised, double-blind study of 86 patients. J Bone Joint Surg Br 1996; 78: 434-40

20. . Ekbäck G, Axelsson K, Ryttberg L, Edlund B, Kjellberg J, Weckström J, et al. Tranexamic acid reduces blood loss in total hip replacement surgery. Anesth Analg 2000; 91: 1124-30.

21. Yamasaki S, Masuhara K, Fuji T. Tranexamic acid reduces postoperative blood loss in cementless total hip arthroplasty. J Bone Joint Surg Am 2005; 87: 766-70.

22. Cid J, Lozano M. Tranexamic acid reduces allogeneic red cell transfusions in patients undergoing total knee arthroplasty: Results of a meta-analysis of randomized controlled trials. Transfusion 2005; 45: 1302-7. 


\section{ORIGINAL ARTICLE}

\section{AUTHORS:}

1. Yashwant Dhawle

2. Ashish Mathur

3. Satish Kumar Ahirwar

\section{PARTICULARS OF CONTRIBUTORS:}

1. Assistant Professor, Department of Anaesthesia, Gandhi Medical College, Bhopal, M. P.

2. Former Post Graduate Student, Department of Anaesthesia, Gandhi Medical College, Bhopal, M. P.

3. Post Graduate Student, Department of Anaesthesia, Gandhi Medical College, Bhopal, M. P.

\section{NAME ADDRESS EMAIL ID OF THE} CORRESPONDING AUTHOR:

Dr. Ashish Mathur, \#15, Adarsh Colony, Gola Ka Mandir, Gwalior-474005, M. P.

Email: ashishgrmc2012@gmail.com

Date of Submission: 01/09/2014. Date of Peer Review: 02/09/2014. Date of Acceptance: 08/09/2014. Date of Publishing: 13/09/2014. 